\title{
Factors affecting acrylamide formation in processed potato products - A simulation approach
}

\author{
Cummins, $E^{* 1}$, F. Butler ${ }^{1}$, N. Brunton ${ }^{2}$ and R. Gormley ${ }^{2}$ \\ ${ }^{1}$ School of Agriculture, Food Science and Veterinary Medicine, \\ University College Dublin, \\ Earlsfort Terrace, \\ Dublin 2, \\ Ireland. \\ ${ }^{2}$ Ashtown Food Research Centre, \\ Ashtown, \\ Dublin 15.
}

*Author for correspondence, email: enda.cummins@ucd.ie

\begin{abstract}
The objective of this study was to create a quantitative farm-to-fork risk assessment model for acrylamide formation in processed potato products (French fries and potato crisps) in order to estimate human dietary exposure to acrylamide from these products and to identify possible risk reduction strategies. Various stages along the French fry and potato crisp making process were modelled, including potato harvest, storage and processing procedures, using Monte Carlo simulation techniques. Inputs were modelled using a variety of probability distributions to account for the inherent uncertainty and variability of the input parameters. The model was developed in Microsoft Excel with the @ Risk add-on package and run for 10,000 iterations using Latin Hypercube sampling. The simulated mean level of acrylamide formation was estimated to be $317 \mu \mathrm{g} / \mathrm{kg}$ in commercially produced French fries and 720 $\mu \mathrm{g} / \mathrm{kg}$ in potato crisps. The models indicated that human exposure to acrylamide through commercially produced French fries may be as high as $0.32 \mu \mathrm{g} / \mathrm{kg}$ bw/day for males and 0.26 $\mu \mathrm{g} / \mathrm{kg}$ bw/day for females. This is below the WHO recommended daily limit of $1 \mu \mathrm{g} / \mathrm{kg}$ bw/day. The level of exposure from potato crisps was significantly less than that estimated for French fries $(0.052 \mu \mathrm{g} / \mathrm{kg}$ bw/day and $0.064 \mu \mathrm{g} / \mathrm{kg}$ bw/day for males and females, respectively). The level of acrylamide in homemade French fries is likely to be high with a mean simulated level of $1073 \mu \mathrm{g} / \mathrm{kg}$. A sensitivity analysis indicated that the initial level of reducing sugars was the most important parameter in both the French fry model and crisp model. The results highlight the importance of cultivar selection and process stages such as reconditioning, blanching, soaking and pre-frying, all of which help to reduce acrylamide formation and are stages which are not typically carried out in the home environment.
\end{abstract}

Keywords: Acrylamide, potato, risk assessment, simulation, Monte Carlo

\section{Introduction}

Acrylamide is a substance classified by IARC (1994) as a potential carcinogen which occurs in heated starchy foods. Acrylamide was first discovered in high concentrations in carbohydrate rich foods (e.g. French fries and potato crisps) by a group of Swedish researchers (Rosen and Hellas, 2002; Tareke et al., 2002) in 2000. Since this discovery, there has been an explosion of interest in this area. As a result, a number of excellent and extensive reviews have been published covering issues such as acrylamide toxicity (LoPachin, 2004), mechanism of formation (Lingnert, 2002) and analysis of acrylamide (Wenzl et al., 2003). 
The pioneering research of Mottram et al. (2002) and Stadler et al. (2002) strongly suggests that acrylamide formation in heated potato products results from the reaction of amino acids such as asparagine (and to some extent glutamine) and reducing sugars (glucose and fructose). Dietary intakes of acrylamide for the general population were estimated by $\mathrm{FAO} / \mathrm{WHO}$ to be in the range of 0.3 to $0.8 \mu \mathrm{g} / \mathrm{kg}$ bw/day (Petersen, 2002). It is clear that the high profile nature of acrylamide in foodstuffs has raised public awareness to a level where further investigation is warranted.

Risk assessment is defined as the qualitative or quantitative estimation of the risk of a particular hazard. It has emerged as a valuable analytical tool for describing the public health consequences of human exposure to food contaminants. Given the potential danger to human health, quantifying consumer exposure to acrylamide is a high priority for governments and the industry alike (Dybing et al., 2005). To date, risk assessment studies on potential acrylamide intake from foods have been published on populations in Belgium (Matthys et al., 2005), Sweden (Svensson et al., 2003, Mucci et al., 2003), Holland (Konings et al., 2003), Germany (Hilbig et al., 2004), Slovakia (Ciesarova et al., 2004), Japan (Maitani, 2004), Norway (Norwegian Food Control Authority, 2002a), the United Kingdom (FSA, 2005), Australia (Croft et al., 2004) and the USA (Petersen, 2002). There is a gap in the scientific literature in terms of the absence of a fully quantitative risk assessment model which combines all components of acrylamide formation and the factors affecting its formation from farm-to-fork. Such an approach would lead to a better understanding of the factors affecting acrylamide formation and enable risk reduction strategies to be identified along the whole farm-to-fork chain. This study aims to address this gap in the scientific literature and provide a comprehensive analysis of acrylamide formation in processed potato products such as French fries and potato crisps. French fries (alternatively fries or chips) are pieces of potato typically $30-100 \mathrm{~cm}$ in length and $5-10 \mathrm{~cm}$ thickness that have been deep-fried at temperatures between $150{ }^{\circ} \mathrm{C}-190{ }^{\circ} \mathrm{C}$ for $5-10$ minutes. They are usually known as chips in the United Kingdom and Ireland or fries in North America. Crisps are a potato snack product popular in the UK and Ireland (referred to in the United States as potato chips). During the crisp production process, immersion of wafer thin slices $(1.5 \mathrm{~mm})$ of potato are heated in cooking oil, typically sunflower oil or rapeseed oil, at high temperatures $\left(175^{\circ} \mathrm{C}-\right.$ $185^{\circ} \mathrm{C}$ ) for times ranging from 2 - 3 minutes.

\section{Materials and Methods}

Data relating to the various stages involved in the French fry and crisp making process was collated from existing scientific literature and relevant stages were modelled with respect to their impact on reducing sugar levels and consequently, acrylamide formation. A flow diagram of the French fry and crisp making processes modelled in this study are given in Figures 1 and 2, respectively.

\section{Reducing sugars}

Glucose and fructose levels were found to be the main determinant factors in acrylamide formation (Amrein et al., 2003; Becalski et al., 2004). Several studies reported a strong correlation between reducing sugars and final acrylamide levels (Amrein et al., 2004b, Matthaus, Hasse and Vosmann, 2004). Given the scientific evidence of a strong correlation between glucose and fructose levels and acrylamide formation, the initial focus of the model was on levels of reducing sugars in raw potatoes and the effect the various processes during French fry and crisp production have on reducing sugar levels. 


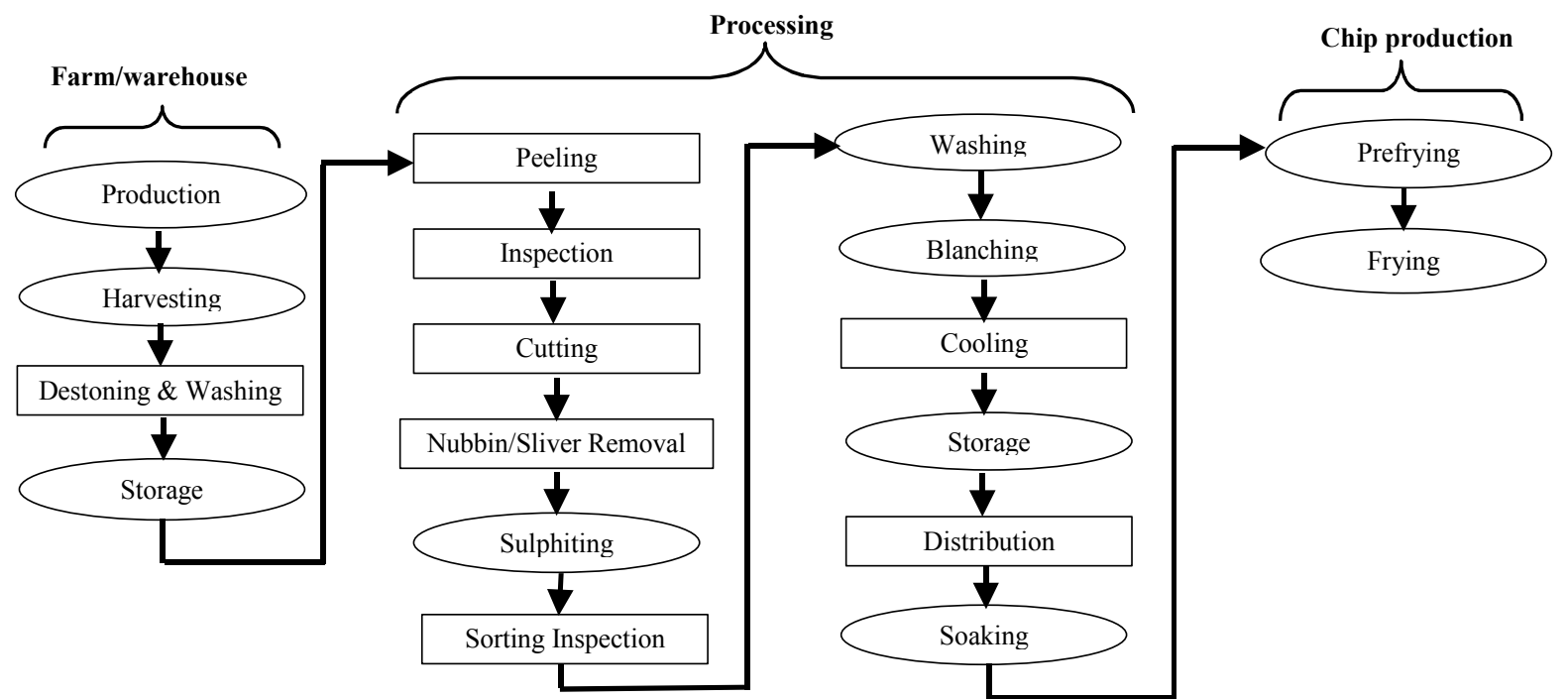

Figure 1: Flow diagram of the production of French fries.

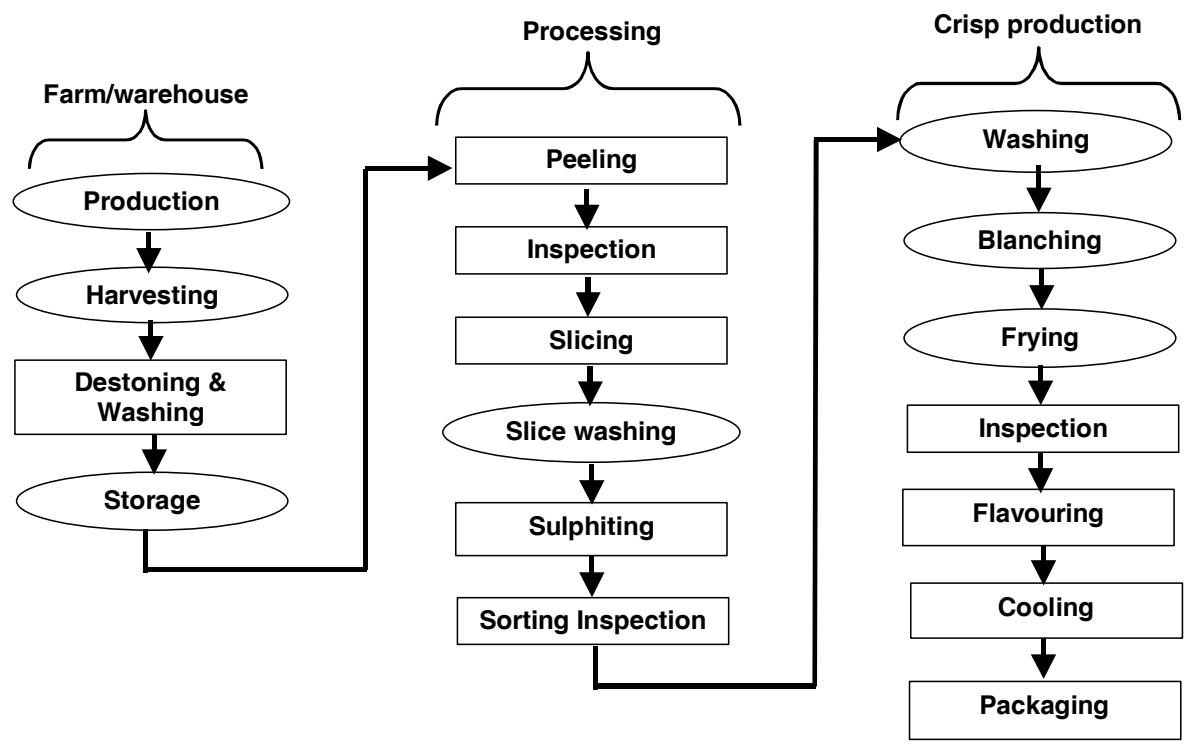

Figure 2: Flow diagram of the production of potato crisps.

\section{Farm production}

Research suggests that sugar contents in potatoes are influenced more by cultivar and storage conditions than any other factor (Amrein et al., 2003; 2004b; Olsson et al., 2004; Becalski et al., 2004). Potato variety can have a significant effect on acrylamide formation as this is correlated with the levels of reducing sugars in the various varieties (Williams, 2005). There is no correlation between potato size and sugars or acrylamide potential (Amrein et al., 2003). Results from Brunton (2006a) gave glucose and fructose levels in Maris Piper potatoes (a variety commonly used for crisp production). The resulting probability distributions were lognormal in shape with a mean of $176 \mathrm{mg} / \mathrm{kg}$ and $180 \mathrm{mg} / \mathrm{kg}$ for glucose $(\mathrm{G})$ and fructose (F), respectively in freshly harvested potatoes. Results from Brunton (2006d) give glucose and fructose levels in Lady Claire potatoes (a variety commonly used in Ireland for crisp production). The resulting probability distribution for the glucose $(\mathrm{G})$ and fructose $(\mathrm{F})$ level in freshly harvested potatoes had a lognormal distribution with a mean of $63 \mathrm{mg} / \mathrm{kg}$ and 61 $\mathrm{mg} / \mathrm{kg}$ for glucose and fructose, respectively. Glucose and fructose are not independent 
variables and a correlation matrix (CF) was used with an $\mathrm{r}^{2}=0.94$ to account for this interaction between glucose and fructose levels, in line with published data (Amrein et al. 2003; Brunton, 2006a; Williams, 2005).

\section{Storage}

When potatoes are stressed (e.g. under cold conditions), starch is broken down to sucrose and eventually to the reducing sugars glucose and fructose (Biederman et al., 2002; Matthaus, Hasse and Vosmann, 2004). Storage at higher temperatures may cause problems in terms of sprouting, resulting in the need for sprouting inhibitors in spring and early summer. The model assumed a storage temperature $\left(\mathrm{S}_{\text {temp }}\right)$ of about $8{ }^{\circ} \mathrm{C}$ to represent typical storage conditions for French fry potatoes and a maximum value of $9{ }^{\circ} \mathrm{C}$. At $8{ }^{\circ} \mathrm{C}$ potatoes will typically start sprouting after 50 days but can typically last up to 100 days. Storage time $\left(\mathrm{S}_{\text {tim }}\right)$ was modelled using a triangular distribution with a minimum of 3 days, a mode of 50 days and maximum of 100 days (Rastovski and van Es, 1987). The resulting time temperature combination was transposed through a storage increase factor (Figure 3) generated from a combination of data reported by Brunton (2006a), Grob et al. (2003), Coffin et al. (1987) and Haase and Weber (2003).

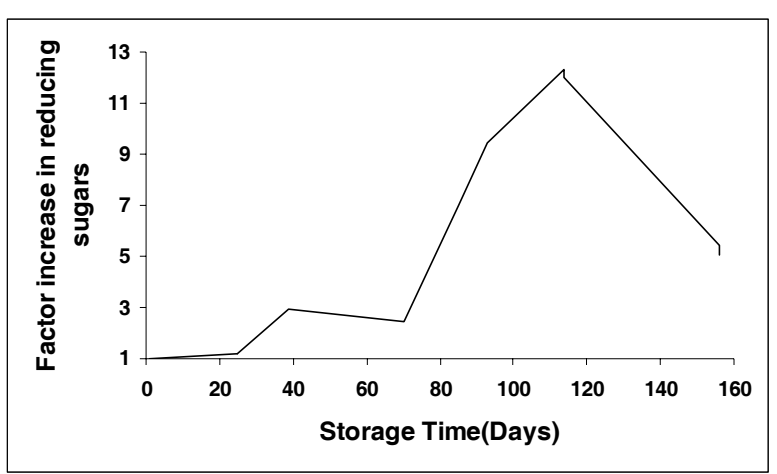

Figure 3: Factor increase in reducing sugars as a function of storage time at temperatures above $8{ }^{\circ} \mathrm{C}$.

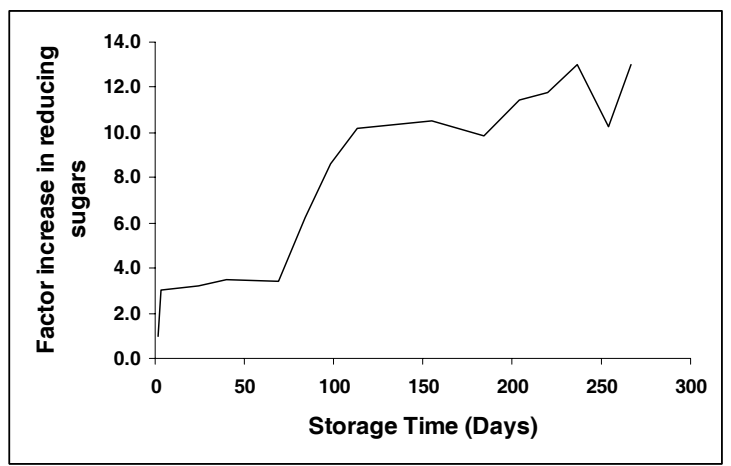

Figure 4: Factor increase in reducing sugars as a function of storage time at temperatures between 3 and $8{ }^{\circ} \mathrm{C}$.

Cultivars used in the crisp trade tend to be stored for longer periods of time than those used for French fries. As a result, these cultivars may need to be stored under refrigerated conditions to avoid sprouting. The temperature can range from $3{ }^{\circ} \mathrm{C}$ to $6{ }^{\circ} \mathrm{C}$ over long storage periods. This lower temperature may significantly influence sugar levels. Brunton (2006d) provided data on the impact of cold storage $\left(3{ }^{\circ} \mathrm{C}\right)$ on reducing sugars for Lady Claire potatoes. An increase of over 10 fold was noticed after 267 days storage at $3{ }^{\circ} \mathrm{C}$. The factor increase in reducing sugars due to storage at low temperatures $\left(<8^{\circ} \mathrm{C}\right.$, Figure 4$)$ is based on cold storage data derived from Brunton (2006d).

Reconditioning refers to the process of storing potato tubers at an elevated temperature (usually greaten than $10^{\circ} \mathrm{C}$ ) for a period of $1-2$ weeks. This can result in a decrease in the reducing sugars level, but tubers will not reach their initial level prior to refrigerated storage (EFSA, 2003; Grob et al., 2003; Coffin et al. 1987). For the French fry model, as the potatoes were stored at $8{ }^{\circ} \mathrm{C}$ it was assumed that reconditioning (R) was not carried out as potatoes stored at temperatures greater that $8{ }^{\circ} \mathrm{C}$ generally do not receive any reconditioning. Given that potatoes stored for the crisp trade are likely to undergo long-term refrigerated storage, there is a need for reconditioning of the potatoes to avoid the formation of brown spots later on during the frying process. For the crisp model, the reconditioning stage (R) was modelled by means of a triangular distribution with a minimum reduction factor of 1 (i.e. no change), a 
mode of 2 (i.e. $50 \%$ reduction) and a maximum of 3 , thus encompassing the best available scientific literature (Coffin et al. 1987; Burton et al., 1992).

\section{Processing}

While the initial processing stages (destoning, peeling, sulphiting) are essential for the production of good quality French fries and crisps, there is no evidence to suggest that any of these stages will influence the reducing sugar levels in the raw potatoes or acrylamide formation in the final fried products. During washing/soaking, water soluble components, such as glucose and fructose, are washed out from the external layer of the potato (Matthaus et al., 2004). Pedreschi et al. (2004) found that glucose content decreased by $32 \%$ in potato slices soaked for 90 minutes and a $25 \%$ reduction following a 40 minute soak in distilled water. Other reducing sugars such as fructose and sucrose followed a similar trend. Grob et al. (2003) reported a reduction in glucose of $6 \%$ and $12 \%$ in fructose following 30 minutes of washing in cold water. To model the sugar reduction following washing (W) and soaking (S) and to model the uncertainty about this parameter, a continuous empirical distribution was fitted to the data provided in the literature in the form of a cumulative distribution (Figure 5). This was used in both the French fry and crisp model.

Blanching refers to the process of immersion of raw vegetables in a heated fluid (either water, oil or an acid) for a period of time. Blanching is used to extract the reducing sugars and asparagines from the surface of potatoes in order to reduce browning, particularly the formation of brown spots (Grob et al., 2003). Another study (Pedreschi et al., 2004) found that blanching reduced on average $76 \%$ and $68 \%$ of the glucose and asparagines content in potatoes, respectively. Trials conducted by Brunton (2006b) found a $28 \%$ reduction in reducing sugars compared to a control following a water blanch at $85{ }^{\circ} \mathrm{C}$ for 3.5 minutes and $21 \%$ reduction for an oil blanch at $150{ }^{\circ} \mathrm{C}$ for 43 seconds. To account for this uncertainty, a continuous empirical distribution, in the form of a cumulative distribution (Figure 6), was fitted to the data from Brunton (2006b) and data provided by others (Pedreschi et al., 2004; Wicklund et al., 2005; Hasse et al., 2003); this was used to simulate the effect of blanching (B) on reducing sugars in the raw potato.

Some cultivars are blanched during the crisping process while other cultivars produce satisfactory crisps without this step, thus reducing processing costs. In the crisp model, blanching was assumed to occur. To account for this uncertainty, a continuous empirical distribution, in the form of a cumulative distribution, was fitted to the data sets from Wicklund et al. (2005) and Pedreschi et al. (2004) and used to simulate the effect of blanching on reducing sugars in the potato crisp.

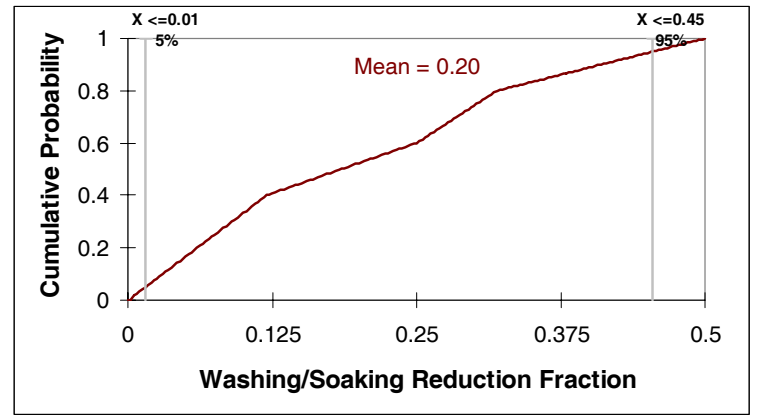

Figure 5: Cumulative probability distribution for washing/soaking reduction fraction.

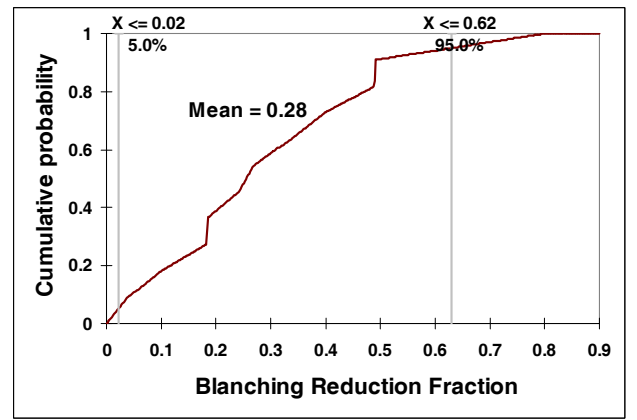

Figure 6: Cumulative probability distribution for the effect of blanching on reducing sugar levels in raw French fries. 


\section{French fry production}

In many cases French fries may undergo a pre-frying treatment at about $140{ }^{\circ} \mathrm{C}$ in order to accelerate the finishing process. Grob et al. (2003) hypothesise that pre-frying results in the formation of a firm tight crust which results in a more visually appealing product for the consumer. The pre-frying stage was incorporated into the model by simulating its effect on acrylamide levels. Uncertainty about the parameter (PF) was incorporated by means of a uniform distribution with a minimum reduction of acrylamide of $40 \%$ and a maximum of $62 \%$, in line with data published by Grob et al. (2003).

There is still considerable uncertainty about the formation of acrylamide and the reaction which takes place following frying. Experimental data shows that it is impossible to determine absolute potential i.e. a complete conversion of the starting materials to acrylamide (Biedermann et al., 2002a); hence, relationships used to convert reducing sugars to acrylamide are purely empirical. This model assumes a linear relationship between total reducing sugar levels (i.e. glucose plus fructose) and acrylamide levels for a particular time and temperature combination. This assumption is supported by previous research conducted by Amrein et al. (2003, 2004b) and Matthaus et al. (2004). This method enables the calculation of an estimate of the level of acrylamide resulting from a particular time temperature regime and for a given level of reducing sugar in the raw potato. A summary of the inputs and relevant distributions used in the French fry model is given in Table 1.

\section{Homemade French fries}

While the consumption of commercially produced French fries undoubtedly represents the greatest consumption of French fries in Ireland, anecdotal evidence suggests that a significant number of people peel, wash and chip potatoes purchased from the supermarket. Cultivars sold in the supermarket may not necessarily have the same low levels of reducing sugars as the cultivars used in commercial production. In addition, potatoes stored at supermarkets may undergo a period of refrigerated storage but will typically not undergo a reconditioning process. Also important process stages such as soaking, blanching and pre-frying are not likely to be carried out in the home environment. All these factors lead to increased reducing sugar levels at the point of frying, with the result that significant acrylamide formation can occur. As an additional exercise, a separate model run was performed using the French fry model scenario described above, with some alterations to reflect the practice of home produced potato French fries.

Data was provided by Brunton (2006c) on the level of glucose and fructose in potatoes bought from a supermarket in Ireland and was used to simulate the glucose and fructose levels in tubers post processing (i.e. parameters $G_{p s}$ and $F_{p s}$ in Table 1). In addition, reconditioning and blanching were assumed not to occur (i.e. $\mathrm{R}=1$ for reconditioning factor and $\mathrm{B}=0$ for blanching reduction fraction). Pre-frying is unlikely to occur in the home environment also, hence the pre-frying reduction (PF) was set to zero. All other parameters are as given in Table 1. 
Table 1: Table of model distributions and inputs for the French fry model.

\begin{tabular}{|c|c|c|c|c|}
\hline Symbol & Description & \multicolumn{2}{|c|}{ Mean value Distribution } & \multirow[t]{2}{*}{ Units } \\
\hline & Harvesting data & & & \\
\hline G & Glucose in raw potato & 176 & Lognormal, standard deviation 77 & $\mathrm{mg} / \mathrm{kg}$ \\
\hline $\mathrm{F}$ & Fructose in raw potato & 180 & Lognormal, standard deviation 86 & $\mathrm{mg} / \mathrm{kg}$ \\
\hline $\mathrm{CF}$ & Correlation factor & 0.9495 & Fixed value & \\
\hline $\mathrm{H}_{\mathrm{f}}$ & Harvest date factor & 1 & Exponential, beta value of 1 & Factor \\
\hline $\mathrm{G}_{\mathrm{ph}}$ & Glucose in harvested potato & & $\mathrm{G} \times \mathrm{H}_{\mathrm{f}}$ & $\mathrm{mg} / \mathrm{kg}$ \\
\hline \multirow[t]{2}{*}{$\begin{array}{l}\mathrm{F}_{\mathrm{ph}} \\
\mathrm{F}_{\mathrm{p}}\end{array}$} & Fructose in harvested potato & & $\mathrm{F} \times \mathrm{H}_{\mathrm{f}}$ & $\mathrm{mg} / \mathrm{kg}$ \\
\hline & Storage & & & \\
\hline $\mathrm{S}_{\text {tim }}$ & Storage time & 90 & Triangular, minimum 3, maximum 186 & Days \\
\hline$S_{\text {temp }}$ & Storage temperature & 8.5 & Triangular, minimum 8 , maximum 9 & ${ }^{\circ} \mathrm{C}$ \\
\hline $\mathrm{S}_{\mathrm{f}}$ & Storage factor & & From table & Factor \\
\hline $\mathrm{G}_{\mathrm{ps}}$ & Glucose post storage & & $\mathrm{G}_{\mathrm{ph}} \times \mathrm{S}_{\mathrm{f}}$ & $\mathrm{mg} / \mathrm{kg}$ \\
\hline $\mathrm{F}_{\mathrm{ps}}$ & Fructose post storage & & $\mathrm{F}_{\mathrm{ph}} \times \mathrm{S}_{\mathrm{f}}$ & $\mathrm{mg} / \mathrm{kg}$ \\
\hline $\mathrm{R}$ & Reconditioning & 1 & Fixed value & Factor \\
\hline $\mathrm{G}_{\mathrm{pc}}$ & Glucose post conditioning & & $\mathrm{G}_{\mathrm{ps}} / \mathrm{R}$ & $\mathrm{mg} / \mathrm{kg}$ \\
\hline \multirow[t]{2}{*}{$\mathrm{F}_{\mathrm{pc}}$} & Fructose post conditioning & & $\mathrm{F}_{\mathrm{ps}} / \mathrm{R}$ & $\mathrm{mg} / \mathrm{kg}$ \\
\hline & Processing & & & \\
\hline $\mathrm{W}$ & Washing reduction & & Cumulative, based on data & fraction \\
\hline B & Blanching reduction & & Cumulative, based on data & fraction \\
\hline $\mathrm{S}$ & Soaking reduction & & Cumulative, based on data & fraction \\
\hline $\mathrm{G}_{\mathrm{pp}}$ & Glucose post processing & & $\mathrm{G}_{\mathrm{pc}} \times(1-\mathrm{W}) \times(1-\mathrm{B}) \times(1-\mathrm{S})$ & $\mathrm{mg} / \mathrm{kg}$ \\
\hline$F_{p p}$ & Fructose post processing & & $F_{p c} \times(1-W) \times(1-B) \times(1-S)$ & $\mathrm{mg} / \mathrm{kg}$ \\
\hline \multirow[t]{2}{*}{$\mathrm{TS}_{\mathrm{pp}}$} & Total sugars & & $\mathrm{G}_{\mathrm{pp}}+\mathrm{F}_{\mathrm{pp}}$ & $\mathrm{mg} / \mathrm{kg}$ \\
\hline & Main Frying & & & \\
\hline $\mathrm{F}_{\text {time }}$ & Time & & Discrete, all $10 \%$ & $\begin{array}{l}\min (5-10 \\
\min \text { only })\end{array}$ \\
\hline $\mathrm{F}_{\text {temp }}$ & Temperature & 180 & Triangular, minimum 160,maximum 190 & ${ }^{\circ} \mathrm{C}$ \\
\hline IP & Intercept & & Uniform $(0,60)$ & $\mu \mathrm{g} / \mathrm{kg}$ \\
\hline RSL & Reference sugar level & & From data, see text & $\mu \mathrm{g} / \mathrm{kg}$ \\
\hline RAL & Reference acrylamide level & & $\begin{array}{l}\text { From data, time } \& \text { temp dependent, } \\
\text { see text }\end{array}$ & $\mu \mathrm{g} / \mathrm{kg}$ \\
\hline $\mathrm{M}$ & Slope & & $(\mathrm{IP}-\mathrm{RAL}) /(0-\mathrm{RSL})$ & \\
\hline A & Acrylamide & & $\mathrm{M} \times \mathrm{TS}_{\mathrm{pp}}+\mathrm{IP}$ & $\mu \mathrm{g} / \mathrm{kg}$ \\
\hline \multirow[t]{2}{*}{$\mathrm{PF}$} & Pre-fry reduction & & Uniform, minimum 0.41 , maximum 0.62 & fraction \\
\hline & Exposu & & & \\
\hline $\mathrm{M}_{\mathrm{m}}$ & Males mean weight (18-64y) & 82.9 & Fixed & $\mathrm{kg}$ \\
\hline IPDM & Intake of product per day & 74 & Lognormal, standard deviation 69 & $\mathrm{~g} / \mathrm{d}$ \\
\hline $\mathrm{M}_{\mathrm{f}}$ & Females mean weight (18-64yr) & 67.5 & Fixed value & $\mathrm{kg}$ \\
\hline IPDF & Intake of product per day & 44 & Lognormal, standard deviation 44 & $\mathrm{~g} / \mathrm{d}$ \\
\hline
\end{tabular}

\section{Crisp production}

Based on available literature, the cooking time and temperature distributions for crisps are detailed in Table 2. For a given time temperature combination, the model simulated acrylamide formation using empirical distributions derived from Granda et al., (2004). A summary of the inputs and relevant distributions used in the potato crisp model is given in Table 2. 
Table 2: Table of model distributions and inputs for the crisp model.

\begin{tabular}{|c|c|c|c|c|}
\hline Symbol & Description & Mean value & Distribution & Units \\
\hline & Harvesting data & & & \\
\hline G & Glucose in raw potato & 63 & Lognormal, standard deviation 43 & $\mathrm{mg} / \mathrm{kg}$ \\
\hline $\mathrm{F}$ & Fructose in raw potato & 61 & Lognormal, standard deviation 48 & $\mathrm{mg} / \mathrm{kg}$ \\
\hline $\mathrm{CF}$ & Correlation factor & 0.9495 & Fixed value & \\
\hline $\mathrm{H}_{\mathrm{f}}$ & Harvest date factor & 1 & Exponential, beta 1 & Factor \\
\hline $\mathrm{G}_{\mathrm{ph}}$ & Glucose in raw potato & & $\mathrm{G} \times \mathrm{H}_{\mathrm{f}}$ & $\mathrm{mg} / \mathrm{kg}$ \\
\hline \multirow[t]{2}{*}{$\mathrm{F}_{\mathrm{ph}}$} & Fructose in raw potato & & $\mathrm{F} \times \mathrm{H}_{\mathrm{f}}$ & $\mathrm{mg} / \mathrm{kg}$ \\
\hline & Storage & & & \\
\hline $\mathrm{S}_{\mathrm{tim}}$ & Storage time & 100 & Triangular, minimum 30, maximum 186 & Days \\
\hline $\mathrm{S}_{\text {temp }}$ & Storage temperature & 4.5 & Triangular, minimum 4, maximum 6 & ${ }^{\circ} \mathrm{C}$ \\
\hline $\mathrm{S}_{\mathrm{f}}$ & Storage factor & & From table & Factor \\
\hline $\mathrm{G}_{\mathrm{ps}}$ & Glucose post storage & & $\mathrm{G}_{\mathrm{ph}} \times \mathrm{S}_{\mathrm{f}}$ & $\mathrm{mg} / \mathrm{kg}$ \\
\hline $\mathrm{F}_{\mathrm{ps}}$ & Fructose post storage & & $\mathrm{F}_{\mathrm{ph}} \times \mathrm{S}_{\mathrm{f}}$ & $\mathrm{mg} / \mathrm{kg}$ \\
\hline $\mathrm{R}$ & Reconditioning & 2 & Triangular, minimum 1, maximum 3 & Factor \\
\hline $\mathrm{G}_{\mathrm{pc}}$ & Glucose post conditioning & & $\mathrm{G}_{\mathrm{ps}} / \mathrm{R}$ & $\mathrm{mg} / \mathrm{kg}$ \\
\hline \multirow[t]{2}{*}{$\mathrm{F}_{\mathrm{pc}}$} & Fructose post conditioning & & $\mathrm{F}_{\mathrm{ps}} / \mathrm{R}$ & $\mathrm{mg} / \mathrm{kg}$ \\
\hline & Processing & & & \\
\hline $\mathrm{W}$ & Washing reduction & & Cumulative, based on data & Fraction \\
\hline B & Blanching reduction & & Cumulative, based on data & Fraction \\
\hline $\mathrm{S}$ & Soaking reduction & & Cumulative, based on data & Fraction \\
\hline $\mathrm{G}_{\mathrm{pp}}$ & Glucose post processing & & $\mathrm{G}_{\mathrm{pc}} \times(1-\mathrm{W}) \times(1-\mathrm{B}) \times(1-\mathrm{S})$ & $\mathrm{mg} / \mathrm{kg}$ \\
\hline $\mathrm{F}_{\mathrm{pp}}$ & Fructose post processing & & $F_{p c} \times(1-W) \times(1-B) \times(1-S)$ & $\mathrm{mg} / \mathrm{kg}$ \\
\hline \multirow[t]{2}{*}{$\mathrm{TS}_{\mathrm{pp}}$} & Total sugars & & $\mathrm{G}_{\mathrm{pp}}+\mathrm{F}_{\mathrm{pp}}$ & $\mathrm{mg} / \mathrm{kg}$ \\
\hline & Main Frying & & & \\
\hline $\mathrm{F}_{\text {time }}$ & Time & & Discrete, $2,2.5,3-10 \%, 80 \%, 10 \%$ & $\min$ \\
\hline $\mathrm{F}_{\text {temp }}$ & Temperature & 180 & Triangular, minimum 160,maximum 190 & ${ }^{\circ} \mathrm{C}$ \\
\hline IP & Intercept & & Uniform $(0,60)$ & $\mu \mathrm{g} / \mathrm{kg}$ \\
\hline RSL & Reference sugar level & & From data, see text & $\mu \mathrm{g} / \mathrm{kg}$ \\
\hline RAL & Reference acrylamide level & & $\begin{array}{l}\text { From data, time } \& \text { temp dependent, } \\
\text { see text }\end{array}$ & $\mu \mathrm{g} / \mathrm{kg}$ \\
\hline M & Slope & & $(\mathrm{IP}-\mathrm{RAL}) /(0-\mathrm{RSL})$ & \\
\hline \multirow[t]{2}{*}{ A } & Acrylamide & & $\mathrm{M} \times \mathrm{TS}_{\mathrm{pp}}+\mathrm{IP}$ & $\mu \mathrm{g} / \mathrm{kg}$ \\
\hline & Exposure assessment & & & \\
\hline $\mathrm{M}_{\mathrm{m}}$ & Males mean weight (18-64y) & 82.9 & Fixed value & $\mathrm{kg}$ \\
\hline IPDM & Intake of product per day & 6 & Lognormal, standard deviation 12 & $\mathrm{~g} / \mathrm{d}$ \\
\hline $\mathrm{M}_{\mathrm{f}}$ & Females mean weight (18-64yr) & 67.5 & Fixed value & $\mathrm{kg}$ \\
\hline IPDF & Intake of product per day & 6 & Lognormal, standard deviation 10 & $\mathrm{~g} / \mathrm{d}$ \\
\hline
\end{tabular}

\section{Exposure assessment}

A consumption survey carried out on the island of Ireland (IUNA, 2001) gave details of the various food products consumed by Irish consumers and the corresponding intake amounts (g/day). Under the category chipped and fried potatoes, the report gave a daily mean intake (IPDM, $\mathrm{n}=662$ ) for males of $74 \mathrm{~g} / \mathrm{d}$ with a standard deviation of $69 \mathrm{~g} / \mathrm{d}$. Similarly for the female population the survey indicated a daily mean intake (IPDF, $\mathrm{n}=717$ ) of $44 \mathrm{~g} / \mathrm{d}$ with a standard deviation of $44 \mathrm{~g} / \mathrm{d}$. Under the category crisps and savory snacks, the report gave a mean intake (IPDM, $\mathrm{n}=662$ ) for males of $6 \mathrm{~g} / \mathrm{d}$ with a standard deviation of $12 \mathrm{~g} / \mathrm{d}$. Similarly for the female population, the survey indicated a daily mean intake (IPDF, $\mathrm{n}=717$ ) of $11 \mathrm{~g} / \mathrm{d}$ with a standard deviation of $16 \mathrm{~g} / \mathrm{d}$. A lognormal distribution was used to model the uncertainty about the intake of French fries and crisps for males and females, using the mean 
and standard deviation quoted in the IUNA survey (IUNA, 2001). Most surveys report exposure in terms of chemical in $\mu \mathrm{g}$ per $\mathrm{kg}$ body weight (Dybing et al., 2005). Therefore, acrylamide exposure is usually expressed in terms of body weight i.e. $\mu \mathrm{g} / \mathrm{kg}$ bw/day. In order to do this, an estimate of the average body weight of both males and females is required. From a sample of 662 males aged between $18-64$, the average body weight $\left(\mathrm{M}_{\mathrm{m}}\right)$ was 82.9 $\mathrm{kg}$. For females, the average body weight $\left(\mathrm{M}_{\mathrm{f}}\right)$ was $67.5 \mathrm{~kg}$ (IUNA, 2001).

\section{Model run}

The input parameters detailed in Tables 1 and 2 were combined onto a spreadsheet (Microsoft Excel 2000) running the @Risk add-on package (Palisade Software, Newfield, N.Y.) and the simulation was performed using Monte Carlo simulation. Monte Carlo methods randomly select values from given distributions to create multiple scenarios of a problem. The simulation was performed using the parameters and calculations presented and the model run for 10,000 iterations. A table of the simulated outputs is given in Table 3.

Table 3: List of simulated model outputs for the French fry and crisp model.

\begin{tabular}{clll}
\hline Symbol & Description & Distribution & Units \\
\hline $\mathrm{A}_{\text {final }}$ & Final Acrylamide in product & $\mathrm{A} \times(1-\mathrm{PF})$ & $\mu \mathrm{g} / \mathrm{kg}$ \\
$\mathrm{IPDM}_{\mathrm{bw}}$ & Intake of acrylamide per day (males) & $\mathrm{A}_{\text {final }} \times \mathrm{IPDM} / \mathrm{M}_{\mathrm{m}}$ & $\mu \mathrm{g} / \mathrm{kg} \mathrm{bw} /$ day \\
$\mathrm{IPDF}_{\mathrm{bw}}$ & Intake of acrylamide per day (females) $\mathrm{A}_{\text {final }} \times \mathrm{IPDF} / \mathrm{M}_{\mathrm{f}}$ & $\mu \mathrm{g} / \mathrm{kg}$ bw/day \\
\hline
\end{tabular}

\section{Results and Discussion}

The model resulted in a number of output distributions which can be used to predict the formation of acrylamide in French fries and crisps and to assess the likely human exposure to acrylamide. Outputs from the model include probability distributions describing acrylamide levels in fried potato products and human exposure to acrylamide from fried potato products.

\section{Acrylamide formation in fried potato products $\left(A_{\text {final }}\right)$}

The simulated probability density distribution describing the uncertainty about the acrylamide level in French fries and crisps is given in Figure 7. The simulated mean acrylamide level in French fries was $317 \mu \mathrm{g} / \mathrm{kg}$. However, there was a large uncertainty distribution generated around this $\left(90^{\text {th }}\right.$ percentile range $\left.36-1003 \mu \mathrm{g} / \mathrm{kg}\right)$. A study by Brunton (2006a) found a range of between $60-720 \mu \mathrm{g} / \mathrm{kg}$ for acrylamide levels in French fries made from Maris Piper potatoes cooked under laboratory conditions simulating the commercial French fry process. This range validates the model estimates. For homemade French fries, the mean level of acrylamide was estimated to be $1073 \mu \mathrm{g} / \mathrm{kg}$. This is over three times the estimated level of acrylamide in commercially produced French fries. The range of acrylamide estimated in home produced French fries, as determined by home cooking trials conducted at the Ashtown Food Research Centre on retail potato varieties Rooster, Record and Oilean, was between 180 and $2970 \mu \mathrm{g} / \mathrm{kg}$ (Brunton, 2006c). This range validates the models estimate and indicates that distributions used for model inputs parameters are justified. The mean simulated level of acrylamide in fried potato crisps was $720 \mu \mathrm{g} / \mathrm{kg}$ (Figure 7). A range of between 650 and 1120 was estimated by Brunton (2006d). The mean level of acrylamide in potato crisps was over twice the level of acrylamide in French fries. 


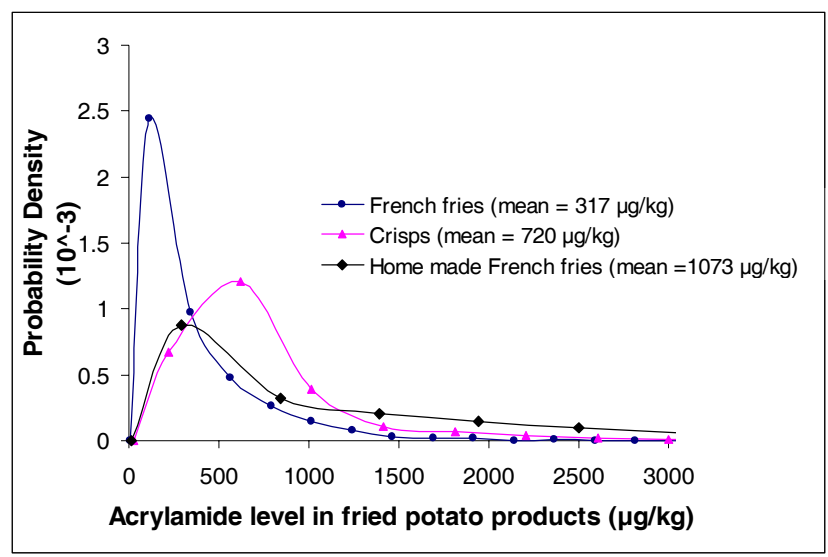

Figure 7: Simulated probability distribution for the acrylamide level in fried potato products.

Acrylamide Daily Intake (IPD)

A probability density distribution describing the daily exposure to acrylamide following the consumption of French fries using Irish consumption data is provided in Figure 8. It is noticeable that females are exposed to smaller levels of acrylamide $(0.20 \mu \mathrm{g} / \mathrm{kg} \mathrm{bw} /$ day $)$ than males $(0.27 \mu \mathrm{g} / \mathrm{kg}$ bw/day). This is mainly due to the greater consumption levels for males when compared with females. This observation is consistent with previous studies, for example the, Norwegian Food Control Authority (2002a) report total intake of acrylamide by males (16 - 30 years) in Norway of $0.53 \mu \mathrm{g} / \mathrm{kg}$ bw/day and $0.33 \mu \mathrm{g} / \mathrm{kg}$ bw/day for females.

The limit of exposure to acrylamide, as suggested by WHO, is $1 \mu \mathrm{g} / \mathrm{kg}$ bw/day (WHO, 2002; Grob et al., 2003). The mean simulated exposure levels for males and females from French fries are well below this limit $(0.27 \mu \mathrm{g} / \mathrm{kg}$ bw/day and $0.20 \mu \mathrm{g} / \mathrm{kg}$ bw/day, respectively). This indicates that eating French fries on its own does not constitute a significant risk to human health for the majority of the human population.

There is a notable lack of data in the literature on the extent of human consumption of home produced French fries. As a result, for this model, human exposure was expressed in terms of $\mu \mathrm{g} / \mathrm{kg}$ bw per portion, (rather than the usual $\mu \mathrm{g} / \mathrm{kg}$ bw/day), thus indicating the likely intake of acrylamide from one portion of home produced French fries (where one portion was taken as $74 \mathrm{~g}$ and $44 \mathrm{~g}$ for males and females, respectively).

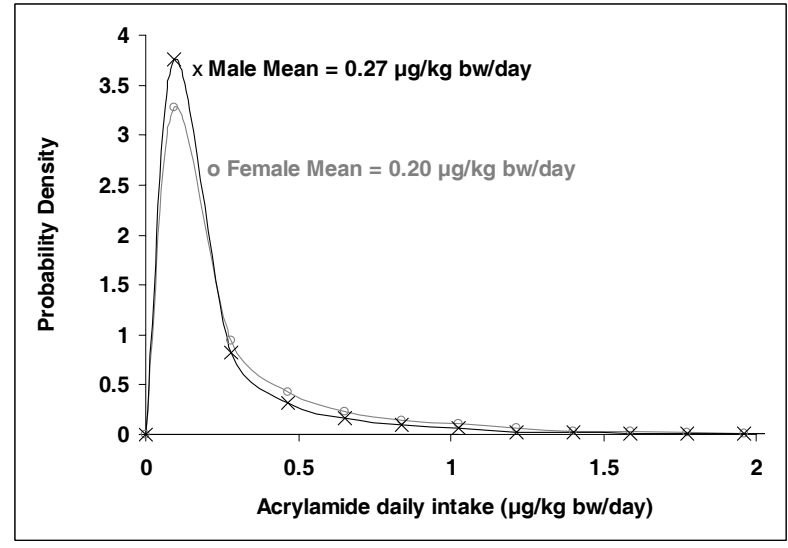

Figure 8: Acrylamide daily exposure for males and females resulting from the consumption of French fries in Ireland.

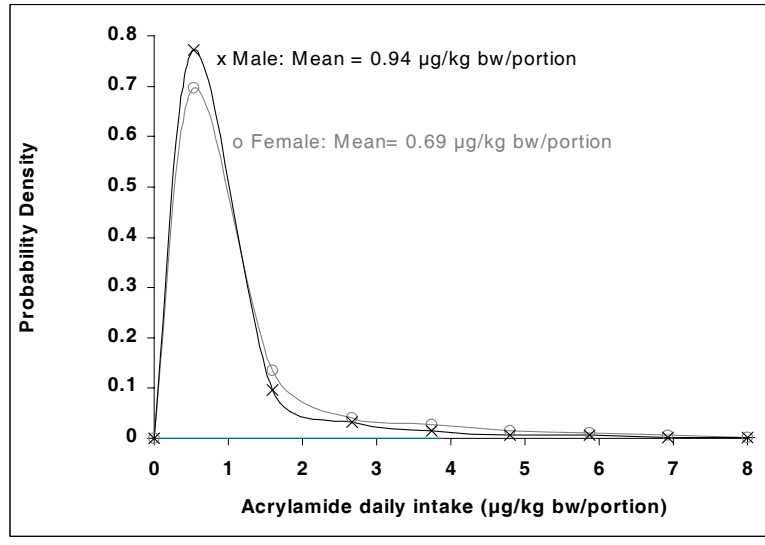

Figure 9: Acrylamide daily exposure resulting from the consumption of a single portion of home produced French fries. 
The simulated human exposure to acrylamide for males and females following the consumption of one portion of home produced French fries is given in Figure 9. The simulated mean exposure level is 0.69 and $0.94 \mu \mathrm{g} / \mathrm{kg}$ bw per portion for females and males, respectively. These results indicate that individuals who prepare their own French fries are likely to be exposed to greater levels of acrylamide in one portion than those who consume commercially produced French fries. This also highlights the importance of process stages such as reconditioning, blanching, soaking and prefrying in reducing the sugar levels and hence the level of acrylamide formation, all of which are not typically carried out in the home environment.

The simulated daily exposure to acrylamide from crisps is given in Figure 10, with a mean exposure of $0.052 \mu \mathrm{g} / \mathrm{kg} \mathrm{bw} /$ day and $0.064 \mu \mathrm{g} / \mathrm{kg}$ bw/day for males and females, respectively. The exposure level is significantly lower than that estimated for commercially produced potato French fries. This is mainly due to the greater exposure levels and portion size for French fries compared to potato crisps. A sensitivity analysis was carried out to evaluate model inputs, parameters and assumptions. The sensitivity analysis for the level of acrylamide in French fries is presented in Figure 11 and for crisps in Figure 12. The analysis revealed that the parameter having the biggest impact on both model predictions was the initial level of reducing sugars present in the potatoes. Uncertainty about cooking time/temperature and blanching regime also have an impact on model predictions. The analysis indicated that by careful selection of cultivars with low levels of reducing sugars, significant reductions in acrylamide can be achieved. It highlighted the importance of the current practice of selecting cultivars with low reducing sugars for the production of French fries. The analysis highlights the need to carefully control the cooking regime in terms of cooking time and cooking temperature and emphasises the importance of processing practices such as blanching, reconditioning and soaking.

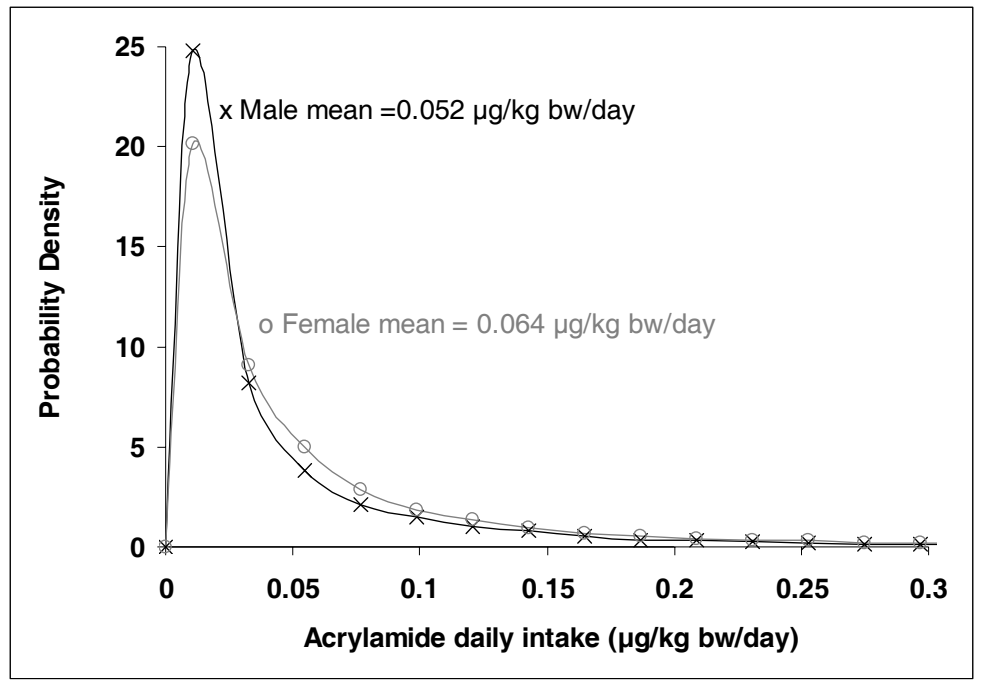

Figure 10: Acrylamide daily exposure resulting from the consumption of fried potato crisps. 


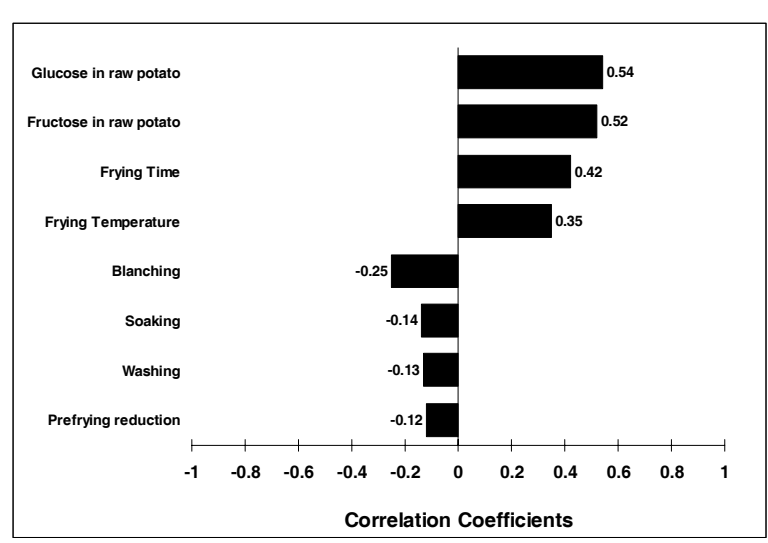

Figure 11: Sensitivity analysis for level of acrylamide in French fries.

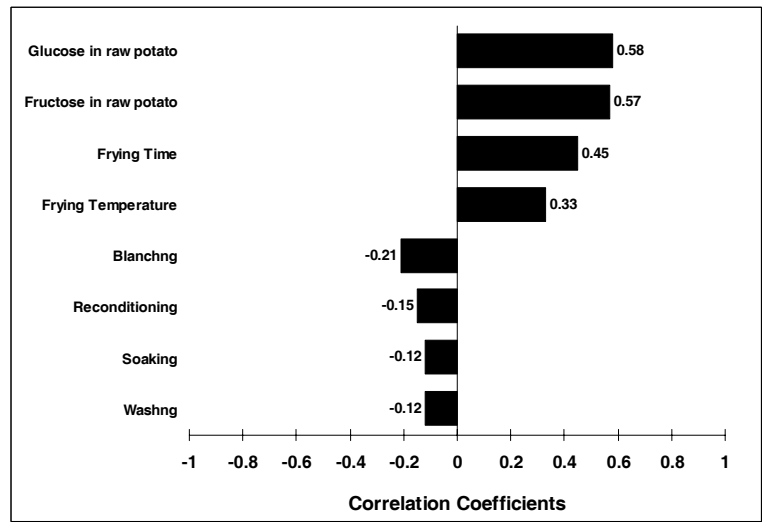

Figure 12: Sensitivity analysis for level of acrylamide in potato crisps.

\section{Conclusions}

This study represents an initial attempt to model the farm-to-fork production of French fries and potato crisps and resulting acrylamide formation, of which there are no other published attempts in the scientific literature. The simulated mean level of acrylamide formation was estimated to be $317 \mu \mathrm{g} / \mathrm{kg}$ for French fries and $720 \mu \mathrm{g} / \mathrm{kg}$ for potato crisps. The models indicated that human exposure to acrylamide through French fries may be as high as 0.32 $\mu \mathrm{g} / \mathrm{kg} \mathrm{bw} /$ day for males and $0.26 \mu \mathrm{g} / \mathrm{kg}$ bw/day for females. This is below the WHO recommended daily limit of $1 \mu \mathrm{g} / \mathrm{kg}$ bw/day, but it does represent $26-32 \%$ of the recommended limit for females and males (WHO 2002). The level of exposure from potato crisps was significantly less than that estimated for French fries $(0.052 \mu \mathrm{g} / \mathrm{kg}$ bw/day and $0.064 \mu \mathrm{g} / \mathrm{kg} \mathrm{bw} /$ day for males and females, respectively). The level of acrylamide in French fries made in the home is likely to be high with a mean simulated level of acrylamide of 1073 $\mu \mathrm{g} / \mathrm{kg}$. Human exposure to acrylamide from one portion of homemade French fries is also likely to be high $(0.94$ and $0.69 \mu \mathrm{g} / \mathrm{kg}$ bw/portion for males and females, respectively).

The sensitivity analysis will be of interest to risk managers trying to devise possible risk reduction strategies. The fact that the level of reducing sugars was the most important parameter identified in the sensitivity analysis in both the French fry model and crisp model indicates that the most effective risk reduction strategy is to select cultivars which are known to have low reducing sugar levels. Traditionally, processors have selected cultivars with low reducing sugar levels for their better storage qualities and ability to produce nicely coloured produce. Thus, processors have inadvertently been selecting cultivars with low potential for acrylamide formation. Optimising the time-temperature regime can also result in significant reduction in acrylamide formation. The sensitivity analysis highlights the importance of process stages such as reconditioning, blanching, soaking and pre-frying, all of which help to reduce acrylamide formation and are stages which are not typically carried out in the home environment.

While significant scientific work has been done on acrylamide and the factors affecting its formation, further research is required, particularly in the area of cultivar selection and cooking conditions optimisation. There is also a need to communicate the risk reduction strategies to the public. In particular, the importance of blanching and reconditioning of retail potatoes before production of home produced French fries should be highlighted. The challenge for food processors and advisory/regulatory agencies is to establish processing protocols that limit the formation of acrylamide while maintaining finished product quality. 


\section{Acknowledgements:}

This project was funded under the Food Institutional Research Measure (FIRM) of the Irish Department of Agriculture and Food as part of the National Development Plan.

\section{References}

Amrein, T., Bachmann, S., Noti, A., Biedermann, M., Barbosa, M., Biedermann, B., Grob, K., Keiser, A., Realini, P., Escher, F. and Amado, R. (2003). Potential of acrylamide formation, sugars and free asparagine in potatoes: A comparison of varietys and farming systems. Journal of Agricultural and Food Chemistry, 51, 5556-5560.

Amrein, T.M., Schonbachler, B., Rohner, F., Lukac, H., Schneider, H., Keiser, A., Escher, F. and Amado, R. (2004b). Potential for acrylamide formation in potatoes: data from the 2003 harvest. European Food Research and Technology, 219, 572-578.

Becalski A., Lau B.P.Y., Lewis, D., Seaman, S.W., Hayward, S., Sahagian, M., Ramesh, M. and Leclerc, Y. (2004). Acrylamide in French fries: influence of free amino acids and sugars. Journal of Agricultural and Food Chemistry, 52, 3801-3806.

Biedermann, M., Noti, A., Biedermann-Brem, S., Mozzetti, V. and Grob, K. (2002). Methods for determining the potential of acrylamide formation and its elimination in raw materials for food preparation, such as Potatoes. Mitteilungen aus Lebensmitteluntersuchung und Hygiene, 93, 653-667.

Biedermann, M., Noti, A., Biedermann-Brem, S., Mozzetti, V. and Grob, K. (2002a). Experiments on acrylamide Formation and Possibilities to Decrease the Potential of acrylamide Formation in Potatoes Mitteilungen aus Lebensmitteluntersuchung und Hygiene, 93, 668-687.

Brunton (2006a). Unpublished data on Trial B: Chip trials. Ashtown Food Research Centre.

Brunton (2006b). Unpublished data on Trial C+: effect of blanching and soaking. Available from Ashtown Food Research Centre.

Brunton (2006c) Unpublished data on Trial C: ware trials, Ashtown Food Research Centre.

Brunton (2006d). Unpublished data on Trial A: crisp trials. Ashtown Food Research Centre.

Burton, W.G., van Es, A. and Hartmans. K.J. (1992). The physics and physiology of storage. In: Harris, (ed.) The Potato Crop. Chapman and Hall, London. pp. 608-727.

Ciesarova, Z., Balasova, V., Kiss, E., Kolek, E., Simko, P. and Kovac, M. (2004). Comparison of two methods for acrylamide determination and dietary intake of acrylamide from potato crisps in Slovakia. Chemical Reactions in Foods, 22, 251-254.

Coffin, R.H., Yada, R.Y., Parkin, K.L., Grodzinski, B. and Stanley, D.W. (1987). Effect of low temperature storage on sugar concentrations and chip color of certain processing potato cultivars and selections. Journal Food Science, 52, 639.

Croft, M., Tong, P., Fuentes, D. and Hambridge, T. (2004). Australian survey of acrylamide in carbohydrate-based foods. Food Additives and Contaminants, 21, 721-736.

Dybing, E., Farmer, P.B., Andersen, M., Fennell, T.R., Lalljie, S.P.D., Muller, D.J.G., Olin, S., Petersen, B.J., Schlatter, J., Scholz, G., Scimeca, J.A., Slimani, N., Tornqvist, M., Tuijtelaars, S. and Verger, P. (2005) Human exposure and internal dose assessments of acrylamide in food. Food and chemical toxicology, 43(3), 365-410.

EFSA (2003). European Food Safety Authority. Workshop on acrylamide formation in food. Report of the workshop. AF 06.04.2004-10, 17 November Brussels.

Food Standards Agency (FSA). (2005). Analysis of total diet samples for acrylamide. Food Survey Information $\quad$ Sheet Available at http://www.food.gov.uk/multimedia/pdfs/fsis712005.pdf

Granda, C., Moreira, R.G. and Tichy S.E. (2004). Reduction of acrylamide Formation in Potato Chips by Low-temperature Vacuum Frying. Journal of Food Science, 69(8), 405411. 
Grob, K., Biedermann, M., Biedermann, B., Noti, A., Imhof, D., Amrein, T., Pfefferle, A. and Bazzocco, D. (2003). French fries with less than $100 \mathrm{ug} / \mathrm{kg}$ acrylamide. A collaboration between cooks and analysts. European Food Research and Technology, 217, 185-194.

Haase, N.U. and Weber, L. (2003) Variability of sugar content in potato varieties suitable for processing. Food Agriculture and Environment, 1(3/4), 80-81.

Haase, N.U., Matthaus, B. and Vosmann, K. (2003). Acrylamide formation in foodstuffs minimising strategies for potato crisps. Deutsche Lebensmittel Rundschau, 99(3), 87-90.

Hilbig, A., Freidank, N., Kersting, M., Wilhelm, M. and Wittsiepe, J. (2004). Estimation of the dietary intake of acrylamide by German infants, children and adolescents as calculated from dietary records and available data on acrylamide levels in food groups. International Journal of Hygiene and Environmental Health, 207, 463-471.

IARC (1994). Acrylamide. Monographs on the evaluation of carcinogenic risks to humans: Some industrial chemicals; International Agency for Research on Cancer; Lyon, France, 60, $389-433$.

IUNA (2001). Irish Universities Nutrition Alliance, North/South Ireland food consumption survey, summary report. Published by: Food Safety Promotion Board, Abbey Court, lower Abbey Street, Dublin 1, ISBN: 9-9540351-0-0.

Konings E.J., Baars, A.J., van Klaveren, J.D., Spanjer, M.C., Rensen, P.M., Hiemstra, M., van Kooij, J.A. and Peters, P.W. (2003). Acrylamide exposure from foods of the Dutch population and an assessment of the consequent risks. Food and Chemical Toxicology, 41(11), 1569-1579.

Lingnert, H., Grivas, S., Jagerstad, M., Skog, K., Tornqvist, M. and Aman, P. (2002). Acrylamide in food: mechanisms of formation and influencing factors during heating of foods. Scandinavian Journal of Nutrition, 46, 159-172.

LoPachin, R.M. (2004). The changing view of acrylamide neurotoxicity. 20th International Neurotoxicology Conference. Neurotoxicity, 25, 617-630.

Maitani, T. (2004). Evaluation of exposure to chemical substances through foods - exposure to pesticides, heavy metals, dioxins, acrylamide and food additives in Japan. Journal of Health Science, 50(3), 205-209.

Matthaus B., Hasse N.U. and Vosmann K. (2004). Factors affecting the concentration of acrylamide during deep-fat frying of potatoes. European Journal of Lipid science Technology, 106, 793-801.

Matthys, C., Bilau, M., Govaert, Y., Moons E., De Henauw, S. and Willems, J.L. (2005). Risk assessment of dietary acrylamide intake in Flemish adolescents. Food and Chemical Toxicology, 43(2), 271-278.

Mottram, D.S., Wedzicha, B.L. and Dodson, A.T. (2002).Acrylamide is formed in the Maillard reaction. Nature, 419, $448-449$.

Mucci, L.A., Dickman, P.W., Steineck, G., Adami, H.O. and Augustsson, K. (2003). Dietary acrylamide and cancer of the large bowel, kidney and bladder: Absence of an association in a population-based study in Sweden. British Journal of Cancer, 88, 84-89.

Norwegian Food Control Authority. (2002a). Risk assessment of acrylamide intake from foods with special emphasis on cancer risk. Available at http://snt.mattilsynet.no/nytt/tema/Akrylamid/acrylamide.pdf

Olsson, K., Svensson, R. and Roslund, C. (2004). Tuber components affecting acrylamide formation and colour in fried potato: Variation by variety, year, storage temperature and storage time. Journal of the Science of Food and Agriculture, 84, 447-458.

Pedreschi, F., Kaack, K. and Granby, K. (2004). Reduction of acrylamide formation in potato slices during frying. Lebensmittel-Wissenschaft and Technologie, 37, 679-685.

Petersen, B. (2002). Exposure and Biomarkers. JIFSAN/NCFST Acrylamide in food Workshop. Available at http://www.jifsan.umd.edu/Acrylamide/acrylamideworkshop.html 
Rastovski, A. and van Es, A. (1987). Storage of potatoes: post-harvest behaviour, store design, storage practice, handling. Pudoc, Wageningen. ISBN 90-220-0897-5.

Rosen, J. and Hellenas, K.E. (2002). Analysis of acrylamide in cooked foods by liquid chromatography tandem mass spectrometry. Analyst, 127(7), 880-882.

Stadler, R., Blank, I., Varga, N., Robert, F., Hau, J. r., Guy, P., Robert, M. and Riediker, S. (2002). Acrylamide from Maillard reaction products. Nature, 419, 449-450.

Svensson, K., Abramsson, L., Becker, W., Glynn, A., Hellenas, K.-E., Lind, Y. and Rosen, J. (2003). Dietary intake of acrylamide in Sweden. Food and Chemical Toxicology, 41(11), 1581-1586.

Tareke, E., Rydberg, P., Karlsson, P., Eriksson, S. and Tornqvist, M. (2002). Analysis of acrylamide, a carcinogen formed in heated foodstuffs. Journal of Agricultural and Food Chemistry, 50, 4998-5006.

Wenzl, T., DelaCalle, B. and Anklam, E. (2003). Analytical methods for the determination of acrylamide in food products: A review. Food Additives and Contaminants, 20, 885-902.

Wicklund, T., Østli, H., Lothe, O., Knutsen, S.H, Bråthen, E. and Kita, A. (2005). Acrylamide in Potato Crisp - The Effect of Raw Material and Processing. LWT - Food Science and Technology, Available online 3 May 2005.

Williams, J.S.E. (2005). Influence of variety and processing conditions on acrylamide levels in fried potato crisps. Food Chemistry, 90, 875-881.

WHO (2002). FAO/WHO consultation on the health implications of acrylamide in food. Summary report of a meeting held in Geneva, $25-27$ June 2002.Available from:http://www.who.int/foodsafety/publications/chem/en/acrylamide_full.pdf. 